Open Access

\title{
Analysis of the ASEAN Banking Integration Framework: the Philippines as a looking glass for consumer preference
}

\author{
Francis Lawrence B. De Jesus ${ }^{*}$ and Enrico Aurelio Torres
}

\author{
* Correspondence: \\ francislawrencedejesus@yahoo.com \\ University of Santo Tomas, The \\ Graduate School, Office for \\ Graduate School Research, 1008 \\ España Blvd, Sampaloc, Manila, \\ Metro Manila, Philippines
}

\begin{abstract}
ASEAN, a region currently undergoing an ambitious integration initiative proposed a unified regional banking system thru the Qualified ASEAN Banks. This brings forth an array of competitive banking alternatives who are now capable of entering new economies within the ASEAN region. Would a local banking customer choose to adhere to the offers of these cross border alternatives or would they stick to their local homegrown banks? With banks from different members of the ASEAN Region as subjects and the local population of the Philippines as respondents, the study yielded the following results;

Upon the full implementation of the ASEAN Banking Integration Framework up to $58.25 \%$ of the local market would diversify their savings resources between local banks and qualified ASEAN Banks, 77.50\% would prioritize Qualified ASEAN Banks for their loans and financing requirements. This brings forth an important contemplation on how local and ASEAN banks should prepare for the full effects of this integration initiative.
\end{abstract}

Keywords: ASEAN, Banking, Philippines, Integration

\section{Background}

Between a local national bank and an ASEAN international bank, which one would a fully integrated ASEAN country citizen prefer once both options are fully within their reach? What offer would they prefer and which one would fall to be a second option? Would they split their savings and loans requirement evenly between the two options? Would they factor in cultural, political or economic differences as deciding factors? These are the questions the study seeks to answer.

The Association of South East Asian Nations (ASEAN) Integration with the ASEAN Economic Community (AEC) as one of its primary supporting pillars envisions to achieve a "freer flow of capital" across ASEAN region (Volz, 2013). It is but normal for an endeavour of this extent to require a unification of its monetary institutions to synchronize developmental goals. With the ASEAN Banking Integration Framework (ABIF) the region hopes to achieve this and more as an effort to uphold the principle of inclusive growth among it's member states. Unfortunately in a local banking competitive environment, the situation is not as simple as it seems. Local banks who have spent considerable

(c) The Author(s). 2017 Open Access This article is distributed under the terms of the Creative Commons Attribution 4.0 International License (http://creativecommons.org/licenses/by/4.0/), which permits unrestricted use, distribution, and reproduction in any medium, provided you give appropriate credit to the original author(s) and the source, provide a link to the Creative Commons license, and indicate if changes were made. 
time solidifying its grasp over its domestic market now faces a considerably greater opponent, most of which are bigger and more liquid in terms of assets and general liquidity.

\section{Narrative sequence}

The study first seeks to establish a level familiarity about the realities that surrounds the integration initiative as the central phenomena. The objective of the study of determining how the local banking competitive environment would be affected by the said initiative is then discussed which includes the hypotheses that would control the flow, pace, and the direction of the study. Literature review that supports the existing biases that is involved with the study and additional factors that needs to be considered in comparing international and local mind sets follows. The methodology that would be used in the primary data solicitation of the study is then discussed followed by the results, which is again guided by the study's hypothesis. Interpretations, recommendations and conclusions are the last part of the paper.

\section{ASEAN Banking Integration Framework 2020 (ABIF)}

In December of 2014, the finance minister of all member states of the AEC created the ASEAN Banking Integration Framework.

The framework's objective was to have a unified banking system across member states by the year 2020. The agreement allowed any two of the original member states of AEC to conduct bi-lateral agreements for greater inter-country unified banking institutional presence to be later merged with other states when they are ready. The framework aimes to endow a certification called a Qualified Asean Banking Status or QAB to local banks who would qualify under certain parameters.

\section{Qualified ASEAN Banks (QAB's)}

Existing banks operating as domestic banks from the original member states of the AEC when endowed with a QAB status would be treated as a local bank of any member country they will enter with unrestricted market access and with no discriminatory treatments by local central banks. QAB is the AFIF's approach towards developing "PAN ASEAN Banks" big enough to compete with global banks from different continents. Local banks in ASEAN may have been developing and growing strongly, however global banks such as Standard Chartered Bank and Citibank still have stronger presence in the region. In this regard, Ravi Menon, Managing Director of the Monetary Authority of Singapore said, "As ASEAN becomes an economic powerhouse, so must our ASEAN banks." (Menon, 2015).

\section{General objectives}

Both the ABIF and the QAB envisions a unified market production base in the form of seamless financial mobility. However while this objectives seems to be pointing towards a progressive future, there are competitive realities that needs to be addressed. Being that the QAB status is going to be limited to a few yet powerful banking entities, there are smaller, local banks who would remain on ground and await the uncertain outcome of a more robust competitive environment for the ASEAB banking sector. 


\section{Research objectives}

Given the light of these realities, there are permanent ways commercial banks builds relationships to increase customer base, customer loyalty, and retention (Osunde, 2014). These ways number among those traits that would be utilized in this current study, attributes which are later on going to be assigned according to the banks whose status and actions reflect those retention strategies and customer acquisition strategies. Among them are their technological factors that improves touchpoints, wide arrays of products and services, emphasis on market position, emphasis on location, even as far as brand ambassadorships. All of these attributes would be put into consideration, bearing in mind the polarity between the local and international mind set.

The researcher conducted a conjoint analysis assisted consumer preference survey for prospective banking offers from both local universal banks of the Philippines and International ASEAN Banks or Qualified ASEAN Banks (QAB's) pre-designed according to the theories of Local Preference Bias (LPB) and Expenditure Switching Effects (ESE).

(LPB) and (ESE) as original theories are discussed and formulated in the succeeding literature review section where the mind-set, the default biases, both in line with local oriented and international oriented preferences of the target market of the integration initiative is discussed.

The results would serve as a basis for the creation of a perception and preference models that would give an accurate forecast of how ASEAN Banks, upon full implementation of the ASEAN Banking integration would fare against the Local banks of the country and how the later can prepare for this new competitive environment.

The following are the hypotheses set to be proven or nullified by the current study;

1. Filipino bank customers still prefers local universal banks over international alternatives. (H1). The first hypothesis envisions a very broad analysis of default preferences between a local and international bank on a free environment option. Meaning no form of intervention is provided. Affirmation of this hypotheses means that there is indeed the default advantage of local banks over international QABs.

2. Filipino banking customers, if asked to open just one savings account whether for business or savings purposes would choose a local universal bank. (H2).The second hypotheses provide a very closed and controlled environment option where the respondent would be asked to choose just one bank among a given choice which includes both local and international banking entities. Affirmation of the said hypotheses would once again prove the existence of local preference bias.

3. Filipino banking customers, if asked to open two or three savings account whether for business or savings purposes would choose one local bank and diversify resources to an international universal bank called Qualified ASEAN Banks (QABs). (H3). The third hypotheses seeks to measure the depth of local preference bias and how several point attribute factors can determine the immensity of the said bias.

4. When applying for a loan, Filipino banking customers would prefer a local bank for their loans and credit needs. (H4). The fourth hypotheses deals with the same conceptual assertion as the first three but this time, focusing on loans instead of savings deposit and general perception. 


\section{Review of related literature}

To be able to expand the academic horizon regarding the phenomena that is the ASEAN Banking Integration Framework (ABIF), the researcher developed two specialized concept that deals specifically with the dilemma about to be faced by Filipino banking customers who will choose between local and international competitors. The first is the Expenditures Switching Effect (ESE) and second is the Local Preferential Bias (LPB) both of which would be the guiding principles in the conjoint analysis performed to complete this study. The following are the research used as basis for the development of the two concepts LPB and ESE.

\section{Local versus international mindset}

(Referring to Hypotheses 1 "On general preferences between local and ASEAN Banks)"

Country of origin effects mandates that local consumers would always treat local service provider differently from international or foreign alternatives. There is a need for an intervention thinking mindset like a local processing mindset in order to lessen the negative impact of country of origin effect framed against the bias of where a particular product is manufactured (Ke Zhong, 2015). The competitive environment scenario being depicted by the AFIF and ABIF mandates an even more intense disparity between the way local consumers feel about a local bank and an international one (QAB). Which of the two would consumers, without any intervention, naturally would prefer? According to John Nofsinger in 2012 thought that consumers generally prefer establishments within close geographic proximity even if presented against higher yield, this is called geographic familiarity bias (Nofsinger, 2012). For banks, the presence of the governing headquarters who house its owners and liable figures were the most important determinant of proximity. Aside from income, cost and documentation, proximity is one of the most important determinant of a client confidence (Gallup, 2015). It is also important to take note of the exclusive nature of a local territory being subjected by the penetraion initiatives of a QAB. Victor Petines describes this exclusivity as a "Destination Market" for a foreign banking institution. According to his study, a destination market was an economy outside a parent mother bank's (QAB) country of origin of operations subject to a QAB's expansion initiative (Victor Petines, 2014) So the closer to home its owners were, the more comfortable consumers feel under geographic bias. Since Customer Perception is the only measure of a successful customer preferences analysis (Seyal, 2011), it would be worthwhile for this study to explore the possibility of these preferential conditions and how the emergence of the QAB's can validate or refute these theories (Gosh, 2014). Another important input regarding this matter is from is from Jiawei Chen (Chen and Song 2013) where they argued that geographic and physical proximity is an important factor for banks and firm partnerships (Chen and Song 2013). It has been found consistently that a greater presence of foreign banks do not harm banking system stability and, under some definitions, and was associated with a statistically significant fall in the probability of a banking crisis (O'Sullivan, 2010).

\section{Brand globalness and local iconess}

(Referring to Hypotheses 1 "On general preferences between local and ASEAN Banks)" Aysegül Ö̈zsomer studied the interplay between global and local brands according to two contrasting concepts. Brand Globalness and Local Iconess. He argued that in 
Studying the mature markets of Singapore and Denmark, he was able to test the chain of relationships that drive consumers' likelihood of purchasing the global brand in a linear structural relations framework. His study's results indicate that perceived globalness is positively related to local iconess in emerging markets but is the opposite in advanced markets (Ö̈zsomer, 2012). The following are some summary of his assumptions;

1. Developing local iconess helps build perception of prestige.

2. Local iconess is positively related to local brand quality for food service but is not significant for non-food products.

His results concerning brand globalness (BG) and local iconess (BI) further challenged the framework laid out by LCCP and GCCP when it comes to the conflicting motivations behind a potential local and international (QAB's) banks imminent domestic class due to ASEAN AFIF and ABIF.

\section{Local consumer culture positioning and global consumer culture positioning}

(Referring to Hypotheses 2 "On specific and exclusive preferences between local and ASEAN Banks)"

Local versus international has been a key subject matter in several studies. Academics and practitioners have long debated the effectiveness of different marketing collaterals on the local versus global appeal perspective (Ford, 2011). Whether or not its for the improvement of the local establishments or the enhanced competitiveness of the international penetrator, a study to analyze these concerns should ask the following key questions according to a study by (Zarantorello, 2014), First On the onset of multi-cultural integration like the ASEAN integration, should marketing collaterals provide a symbol of globalization over local consumer positioning? Second, should they emphasize on features and benefits or should they focus more on the emotional aspects of the said comparison (Zarantorello, 2014). All of these are factored in consideration with different countries' different political landscape which is, according to a study is the most influential when it comes to economic growth (Sarwar and Haq, 2017).

Charles Taylor and Shintro Okazaki made a comprehensive study about the key differences between brand perceptions across cultures. On their study they cemented two important concepts that are now in material literature circulation. Firstly, is the Local Consumer Culture Positioning (LCCP) where a company intentionally does not make association with globally shared cultural meanings but rather focus on meaning shared within a local culture. Secondly the GCCP or the global consumer culture positioning which is a result of increased shared consumption beliefs and shared behaviours. Firms now benefit from a global standard in brand association with languages, aesthetics and themes (Taylor, 2015).

\section{Ethnocentrism and globalization}

(Referring to Hypotheses 3 and 4 "On limited and specified preferences between local and ASEAN Banks)"

Ethnocentrism is a self-defense reflex of local economies against the threat of foreign competition (Everret, 2015). But is this way of thinking still applicable on 
the onset of an integration? Analysis of a consumer's inclination towards adhering more to either local home-grown establishment or their globally sourced counterparts is important now more than ever. For this part of the literature review Ethnocentrism is taken against globalization. Ethnocentrism as a concept argues that many consumers prefer domestic over foreign offerings even when the quality is lower and the price is higher.

Ethnocentrism is a competent indicator of inclinations toward the locally grown alternatives. In the study of Plavini Punyataonya in 2013, he argued that there was a current trend towards globally oriented brands and these are now taking a center stage position.

Globalization on the other hand mandates that consumers should develop similar taste across countries, increases consumer desires for globally imaged products and increases the similarity of lifestyles across the world (Punyatoya, 2013).

\section{Perceived Brand Foreignness (PBF) and Confidence in Brand Recognition (CBR)}

Lianxi Zhou et al., investigated brand origin as an identifying factor in consumer confidence and preference. Two material concepts were born out of this: "PBF" or Perceived brand foreignness, and "CBO" or Confidence in Brand Origin Identification. Both of these metrics are important in identifying inclinations towards local and non-local offerings (Lianxi, 2010).

These metrics points out eventually to the attributes that would be assigned in the survey materials that would be used in this study.

In the case of the ASEAN Integration's ABIF and AFIF who aims to eventually arrive at QAB's will the western inclination towards colonial mentality serve as a material determinant of the LCCP and the GCCB as a strategic approach towards the development of both parties. Here ethnocentrism place an important role. These behaviour analysis tools are important for QAB's who are about to enter the Philippines. According to Misbah Khalid and Saleem Un Rahman. The theory of planned behaviour involves 3 factors. First is the perceived risks which very much imminent when dealing with banks and most specially true when contemplating on where the bank is from. Second is word of mouth. For this second one both local and QAB's may be at par in terms of advantage and handicap. Third is emotions, for emotions things gets a little more complicated. This is where factors like love of country or colonial mentality would come in.

More in the case of ethnocentrisim for Islamic nations with banks who are sharia compliant, a much more complicated spread of issues are involved with regards to market acceptance for new banking alternatives most of which are issues that restricts them due to their closed culture of patronage. Mostly these sharia banks have challenges when it comes to establishing linkages and external investments (Abdullahi, 2016). And while Islamic banks are not immune to financial crisis (Mongid, 2016), Islamic banks is still an integral part of the ASEAN financial region that has proven it's resilience.

\section{Research methodology}

The objectives for the conjoint analysis component of the study remains uniform with its general objectives, that is to determine if regular potential bank customer respondents are likely inclined towards either 
1. Expenditure Switchers Effect (ESE) "Inclination Towards ASEAN QAB'S"

2. Local Preferential Bias (LPB) "Inclinations towards being loyal to local banks"

Determination between Local Preference Bias and Expenditure switcher's effect is applicable for two core bank business and would be reflected on the face as feature of the cue cards to be used in the study. As established under the concept of ESE and LPB, Philippine local unibanks would bear a generally lower value proposition as compared to their $\mathrm{QAB}$ equivalent.

a. First is on Deposits

b. Second is on Loans

There are three points of inquiry regarding deposits first is on Familiarity or recognition of the bank itself, second is on preference (likelihood to transfer all or single accounts). And lastly on diversification or the likelihood to open a secondary account therefore splitting deposit volume/ loan potential.

Researcher used visual cue cards that would be arranged in a hierarchal order from most preferred/recognized to least.

There are a number of banks that the researcher can use as the subjects for this study, however due to the constraints of the 10 maximum slots for the methodology that would be used and the visual assisted cue cards portion of it so as not to overwhelm the respondents with options, the researcher selected the following banks based on their size, status of qualification to become a $\mathrm{QAB}$, and their branch network distribution (especially for the international ones) as the subject of the study (Table 1).

The researcher purposively selected the banks as they are scattered across ranking based in assets, receivables, and branch network in order to see if there is a relationship between the result of the study and the financial and physical distribution strength of the banks. Due to the limitation of the number of cards that can be presented for the conjoint analysis survey, the researcher had to use purposive sampling that aims to represent the different banks based on their various strength and financial capacity.

\section{Mechanics}

The researcher selected 400 Filipinos of legal age existing or potential bank customers as the study's respondents using hierarchal Bayesian (HB) as a method of determining sample size.

Divided as Group A "Personal Savings Capacity" and Group B "Business Banking Capacity". For the serve as a qualifying question, the researcher would ask respondents whether they are familiar with a revolving credit facility. If the answer is no, then they are assigned the savings capacity status while if the answer is yes then it means they are knowledgeable with business related banking transactions.

All questions was asked using English as the universal language. Likewise the cue cards are all prepared using English as the medium of illustration.

On the first round (SCENARIO A) the respondents would be asked to arrange a set of 10 cue cards on a hierarchy basis according to how they generally feel about the bank based on their own unspecified and unrestricted personal justification. 
Table 1 Subject bank profiles (based on 2016 annual report consolidated through the Bangko Sentral ng Pilipinas (Central Bank) for the local banks and individually sourced from 2016 year end reports for international banks

\begin{tabular}{|c|c|c|c|}
\hline \multicolumn{4}{|l|}{ LOCAL BANKS OF THE PHILIPPINES (Assets) } \\
\hline Bank & Code/Class & $\begin{array}{l}\text { (Millions of USD as } \\
\text { of August } 4,2017 \text { ) }\end{array}$ & Rank based on assets \\
\hline BDO UNIBANK INC (740 Branches) & L1 Loc & $429,92.97$ & 1 \\
\hline METROPOLITAN BANK \& TCO (815 Branches) & L2 Loc & $303,64.16$ & 2 \\
\hline PHIL NATIONAL BANK (670 Branches) & L3 LoC & $139,11.31$ & 5 \\
\hline SECURITY BANK CORP (291 Branches) & L4 LoC & $136,05.73$ & 6 \\
\hline $\begin{array}{l}\text { UNITED COCONUT PLANTERS BANK } \\
\text { (188 Branches) }\end{array}$ & L5 Loc & $57,054.43$ & 12 \\
\hline \multicolumn{4}{|c|}{ LOCAL BANKS OF THE PHILIPPINES (Loans and Receivables) } \\
\hline Bank & Code/Class & $\begin{array}{l}\text { (Millions of USD as } \\
\text { of August } 4,2017 \text { ) }\end{array}$ & Rank based on receivables \\
\hline BDO UNIBANK INC (740 Branches) & L1 Loc & $272,60.35$ & 1 \\
\hline METROPOLITAN BANK \& TCO (815 Branches) & L2 LoC & $146,99.97$ & 2 \\
\hline PHIL NATIONAL BANK (670 Branches) & L3 Loc & $69,53.30$ & 5 \\
\hline SECURITY BANK CORP (291 Branches) & L4 LoC & 5639.18 & 7 \\
\hline $\begin{array}{l}\text { UNITED COCONUT PLANTERS BANK } \\
\text { (188 Branches) }\end{array}$ & L5 Loc & 3284.02 & 11 \\
\hline \multicolumn{4}{|l|}{ QUALIFIED ASEAN PRIVATE BANKS IN ASIA (Assets) } \\
\hline Bank & Code/Class & (Billions of USD) & Rank based on assets \\
\hline $\begin{array}{l}\text { DBS GROUP (Singapore) ( } 280 \text { Branches } \\
\text { in } 18 \text { Countries) }\end{array}$ & Q1 QAB & 338.75 & 28 \\
\hline $\begin{array}{l}\text { MAYBANK (Malaysia) ( } 2200 \text { Branches } \\
\text { in } 20 \text { Countries) }\end{array}$ & Q2 QAB & 181.45 & 42 \\
\hline $\begin{array}{l}\text { BANGKOK BANK (Thailand) (1232 in } \\
15 \text { Countries) }\end{array}$ & Q3 QAB & 83.51 (Million USD) & 74 \\
\hline $\begin{array}{l}\text { BIDV (Vietnam) (130 Branches in } \\
3 \text { Countries) }\end{array}$ & Q4 QAB & 37.80 (Million USD) & 130 \\
\hline BAIDURI (Fictional) & Q5 QAB & VOID CARD & - \\
\hline
\end{tabular}

On the second round (SCENARIO B, B1-2) the respondents would simply choose a specified number of cards based on three core positions.

a. If you would open and maintain just ONE savings account what bank would you choose

b. If you would open and maintain TWO savings accounts what bank would you choose

c. If you would open and maintain THREE savings accounts what bank would you choose

On round three (SCENARIO C) the respondents would simply choose a specified number of cards based on just one core position.

a. If you are to apply for a loan, where would you apply? (CHOOSE ONE)

Free form or open ended response was given by the respondents to justify their options. These would be tabulated and appreciated via frequency analysis. 
Any attributes and actual promotional initiatives of the subject banks are reflected on the cards and the respondents are the ones who would determine if these attributes, based on their own perception is indeed strong and appealing for them. This is to avoid researcher induced biases.

\section{Results}

The research encourages the population of respondents to arrange and or choose from a set of 10 visual cue cards. Five of which represents local universal banks and five representing the international Qualified ASEAN Banks (QABs). This was performed a total of four times by the respondents with 3 Scenarios as mandated by the research objectives and to support the hypothesis.

Using SPSS, the researcher ran the tabulated conjoint analysis database and the following was observed as a result.

It is important to note that Card Q4 is a void card, it carries no significance but it monitors response integrity.

\section{SCENARIO A "Rank subjectively based on Preference and Visual Impressions"}

Summary of response of Scenario A which is in fulfilment of the study's first hypothesis "Would a Filipino prefer local universal banks given their international competitor's stronger capabilities value proposition wise" Supported by the conceptual framework Local Preferential Bias (LPB) versus Expenditures Switchers Effect (ESE).

The respondents was asked to arrange the cards in order from rank 1 to rank 10 rank 1 being the most favored while rank 10 least favored based on their preference and how they appreciate the visual appeal of the cards presented. The following were the results:

The top five ranks was occupied by the five cards representing the local universal banks.

1. BDO for rank number 1 taking $30.50 \%$ of all response.

2. Metrobank for rank number 2 taking $34.50 \%$

3. PNB for rank number 3 taking $23.50 \%$

4. Security Bank for rank number 4 taking $17 \%$

5. UCPB for rank number 5 taking $28 \%$

Meanwhile the highest spot the an International Bank occupied is rank 6 by Development bank of Singapore with $26.50 \%$ the other four QABs taking the last six ranks.

\section{SCENARIO B "Choose one Bank unto which you will maintain one savings account" Lone option}

For scenario B, the respondents were asked to choose between the bank options given the requirement that they would maintain only just one account. Local preferential bias, one of the core theoretical concepts of the study mandates the support for the hypothesis that the local ones are the probable option for this round.

The results are as follows: 
The top three spots is strongly occupied by local universal banks, L1 BDO with 42\%, L2 Metrobank with 25.50\% and L3 PNB bank with $12.5 \%$ meanwhile the fourth spot was occupied by a QABs with $10.50 \%$ by Q1 Development bank of Singapore and Local bank L4 Security Bank with 4.25\%.

Local unibanks garnered in general $86.25 \%$ while the QAB's shared with the remaining $13.75 \%$.

Due to the expectations of Local preferential bias, this result upholds the study's hypothesis that with just one account to maintain, local universal banks would definitely be preferred. This supports the reality that most of these local banks may currently be the actual banks of the respondents. The real contemplations are expected to occur in the succeeding rounds where Local Preferential bias or LPB would be challenged by Expenditures Switchers Effect ESE.

\section{Scenario B1}

Summary of the responses on Scenario B1 "Choose two savings account to maintain".

\section{First option}

For choosing two banks unto which they would maintain two saving accounts, the results were as follows for first choice:

Top three spots is still occupied by three local unibbanks, L2 Metrobank with 39\%, L1 BDO with 33.75\% and L3 PNB with 9.25\%. The fourth spot was once again occupied by a QAB Q1 Development bank of Singapore with 7.75\%.

In summary all Local Unibanks got $87.25 \%$ while all QABs shared with the remaining $12.75 \%$.

It can be noticed that the results for the first choice resembles the results of the "choose one" scenario.

\section{Second option}

This part of the study is a crucial determinant of whether the loyalty of Filipino bank customers would remain with a local universal bank, upholding Local Preferential Bias (LPB) or would they decide to diversify and split their savings resources and entrust them to international players during the implementation of the ASEAN Banking Integration Framework.

For the second option under the scenario, choose two banks where you would maintain two savings account, the result shifted moderately. The top two options was still maintained by local unibanks, L1 BDO with $37.25 \%$ and L2 Metrobank with $23.50 \%$, the third spot is now taken by a QAB QI Development bank of Singapore and the fourth slot also taken by a QAB Q2 Maybank 9.25\%.

Overall share per group is $72.5 \%$ for all five Local unibanks and $27.5 \%$ for all QABs.

\section{Scenario B2}

Summary of the responses on Scenario B2 "Choose Three Savings Account to Maintain".

A more in depth look unto how the market will react, the respondents was now asked to imagine maintaining three savings account among the given options. 


\section{First choice}

The first choice given for the question, if you are to maintain three saving account, which banks would you choose, the top 2 spots both goes to Local Universal banks L1 BDO with $35.50 \%$ and L2 Metro Bank with 32.25\%. The third spot was occupied by a QAB, Q1 Development Bank of Singapore with 13\% while the fourth and the fifth spot where both occupied by local unibanks. Local unibanks in general garnered $84.25 \%$ for the first choice while all QAB's got $15.75 \%$.

The first choice always depicts historically the most preferred option. Meanwhile diversification is most of the time determined in the second and the third options.

\section{Summary of the responses on Scenario B3 "Choose Three Savings Account to Maintain" Second choice}

The second Choice for the scenario somehow resembles the first option in terms of rank as the first two spots where once again occupied by local unibanks. L2 Metrobank at $27.75 \%$ and $\mathrm{L} 1 \mathrm{BDO}$ at $24.75 \%$. The third spot was again taken by QAB Q1 Development Bank of Singapore at $19.75 \%$, it can be noted however that there is already a noticeable leap when it comes to the share of the QABs on this round. All QAB's now garnered 36\% while in the first choice round they only got 15.75, meanwhile the share of Local Unibanks dropped from 84.25 on the first round to $64 \%$ on the current round.

\section{Summary of the responses on Scenario B3 "Choose Three Savings Account to Maintain" Third choice}

Similar to the second choice for the previous scenario, the third and last choice is crucial in determining how much is a Filipino willing to diversify in terms of splitting savings resources once the universal playing field is expanded to international players.

For the third choice round, QAB's was able to take the lead from the local universal banks. When asked to maintain three savings account, the third option bank ranking was reversed from the previous rounds. The top two spots are now occupied by two QAB's namely Q1 Development Bank of Singapore and Q2 Maybank with 39.25\% and $19 \%$ respectively. The third and the fourth spot was taken by the local unibanks L1 BDO at $13.25 \%$ and L2 Metrobank at $12.25 \%$. All QABs overtook majority of the response with $65 \%$ of total choices while the local banks shared with the remaining $35 \%$.

\section{SCENARIO C "On Loans and Credit which one bank would you prefer"} Summary of the responses on Scenario C "Choose 1 Bank for Loans and Credit Needs"

For scenario $\mathrm{C}$, there has been a major reversal of trend when it comes to the choice given by the respondents. When asked what bank they would choose if they are to apply for a loan, 52.25\% of Filipino respondents would prefer Q1, Development Bank of Singapore which is an international Qualified ASEAN Bank, the runner up with $12.25 \%$ is May Bank also a QAB, while the highest rating a local unibank garnered is a modest $9.75 \%$ by BDO. The total percentile per group is $77.5 \%$ for all five QAB's while Local unibanks got $22.5 \%$.

On respondent cluster homogeneity or heterogeneity:

The researcher observed moderate homogeneity with the maximum difference between the savings profile respondent group and the business profile respondent group 
pegged at $15 \%$ with a single occurrence and an average of $3.5 \%$ difference across all scenarios.

On the eight occasions where the respondents was asked to choose a specific bank being represented by a visual cue card, the following were the once placed in the top spot, they are placed together with the attribute assigned to them.

Table 2 illustrates the said itemized ranking of attributes as they are solicited from the respondents based on card assignments.

With the consideration of both the market and the local banking managements perspectives taken from the two sets of primary data presented, the researcher now utilizes the extent of the conjoint analysis study by further analyzing the attributes assigned to each bank representatives as an effort to conjure a reactive model that may benefit banks who will undergo revisions of their respective competitive environments brought about by stiffer competition.

\section{Top Value Added Attribute per Rank}

The following are the most desired attributes of the customers regardless of affinity (whether they are local of international)

First Place - The value added attribute assigned to Local Universal Bank BDO depicts expansion of banking services currently offered by the bank which includes $12 \mathrm{~h}$ banking, mall branches, weekend bank operations all of which are reflected on the visual cue card L1. With the top responses average of $27.6 \%$ expanded value added service is the most important attribute for the respondents.

Second Place - The value added attribute assigned to Local Universal Bank Metrobank educates the respondents about their continued Philippine market supremacy for the past decade. No other attribute is assigned it. Coming in second at $23.75 \%$, superiority in the local banking industry is the second most important factor for the respondents. Third Place - The value added attribute assigned to Qualified ASEAN Bank DBS. Educates the respondents with the fact that DBS is currently the biggest and most liquid bank in all of Asia. Garnering a mean response of $22.96 \%$, market superiority on an international scale is the third most important attribute for this set of respondents.

Table 2 Attribute ranking

\begin{tabular}{llll}
\hline CARD ID & Bank & Value Added Attribute Assignment & Percentile Mean \\
\hline L1 Loc & BDO & Expanded Range of Services & $\mathbf{2 7 . 6}$ \\
L2 Loc & Metrobank & Local Market Superiority & $\mathbf{2 3 . 7 5}$ \\
Q1 QAB & DBS & Asian Market Superiority & $\mathbf{2 2 . 9 6}$ \\
Q2 QAB & Maybank & Superior QAB Value Offer & $\mathbf{8 . 8 9}$ \\
L3 Loc & PNB & Brand Ambassadorship & $\mathbf{7 . 3 9}$ \\
L4 Loc & Security & Touchpoints Convenience & $\mathbf{3 . 5 3}$ \\
L5 Loc & UCPB & Freebies and Comfort & $\mathbf{1 . 6}$ \\
Q5 QAB & Baiduri & Void & $\mathbf{1 . 3 9}$ \\
Q3 QAB & Bangkok Bank & Foreign Appeal & $\mathbf{1 . 1 4}$ \\
Q4 QAB & BIDV & Cultural/Ethnic Diversity & $\mathbf{1 . 1 2}$ \\
\hline
\end{tabular}

Content of the table in bold are the frequencied summary of findings 
Fourth Place - Qualified ASEAN Bank Maybank contains an attribute that depicts the capability of a QAB to give superior offers. Specifically, their active double your deposit initiative is on the card's face. With $8.89 \%$, this feature is the fourth most important attribute.

Fifth Place - Local universal bank PNB with a $7.39 \%$ mean rating indicates that the popularity of the bank ambassador/endorser is the fifth most important attribute. Sixth Place - Sixth most important attribute is touchpoint convenience with 3.53\% mean rank, local universal bank security bares a feature on its card information about how easy it is to open a bank account with them with only one valid id as a requirement and no forms to fill up for every transaction.

Seventh Place - Local Universal banks UCPB's free coffee and no standing que representing the freebie and comfort attribute for all customers was among the least favored attribute with only $1.6 \%$ mean rank.

Eight Place - Baiduri Bank, a QAB to be from Brunei Darussalam and it's ethnic sensitive attribute was ranked least by this set of respondents with $1.39 \%$

Ninth Place - Bangkok Bank's visual cue card contains no other attribute aside from its foreign identity fulfilling the need for a default international attribute. This was also among the least noticed by the respondents with $1.14 \%$.

Tenth Place - The void card, which contains virtually no information aside from the name of the bank and a confusing value offer ranked last with $1.12 \%$ indicating that the logical soundness and integrity of all 400 respondents was generally sound.

\section{Top verbatim response recorded}

The verbatim response of the subjects were recorded and frequencied for supplemental purposes only. The following was not integrated on any of the statistical treatment of the core data that was solicited.

1. Branch Network is unbeatable as a factor $0.097539 / 400$

2. Will choose international banks for extra savings 0.0725 29/400

3. Will choose international banks for loans because its easier $0.0624 / 400$

4. Local banks are difficult to deal with when it comes to loans $0.047519 / 400$

5. I don't know these international banks $0.032513 / 400$

With regards to the relationship between the branch network distribution, assets, and loan portfolio of the banks with the preferential results of the study, the researcher found significant relationship for local universal banks and no statistical significance for QABs.

For a more in depth analysis of the relationship between the joint data sets sourced from the core scenario survey and the attribute analysis data, the researcher utilized the McNemar Test for Binary Matched Pair. The pair being $\mathrm{N}=$ The total number of response that points out towards a local bank being selected (n1) under the prescribed scenarios taken against the response where a $\mathrm{QAB}$ was chosen (n2) and $\mathrm{P}=$ being the number of times the attribute selected as most compelling is present in a local bank cue card (p1) taken against the instance the said top attribute is associated with a QAB cue card (p2). Findings are illustrated as follows (Table 3): 
Table 3 McNemar Test of Preferential Attribute Randomness

\begin{tabular}{lllll}
\hline \multicolumn{5}{l}{ McNemar Test } \\
\cline { 2 - 5 } & \multicolumn{4}{l}{ Scenario Based Preference Selection } \\
\hline Attribute Recognition & Response & Chose Local & Chose International (QAB) & Sum Population \\
& Attribute Present in Local & 2246.56 & 1017 & 3263.56 \\
& Attribute Present in & 2119.44 & 1153.44 & 3272.88 \\
& International (QAB) & & & 6536.44 \\
& Sum & 4366 & 2170.44 & \\
\hline
\end{tabular}

Under the assumption of the following hypothesis as discussed:

H1, H2 and H3 (General Preference, Select $1,2,3)=(\mathrm{n} 1>\mathrm{n} 2)$ and $(\mathrm{n} 1+\mathrm{p} 1)>(\mathrm{n} 2+\mathrm{p} 2)$ are all affirmed by the match paired findings.

H4 $($ Loans $)=(\mathrm{n} 1>\mathrm{n} 2)$ and $(\mathrm{n} 1+\mathrm{p} 1)>(\mathrm{n} 2+\mathrm{p} 2)$ has been nullified.

\section{Interpretation and Discussions}

The first three hypotheses of the study points towards a prospective bias in favor of local universal banks when it comes to control of savings and similar deposit resources of the respondents. With variations that includes the prospective splitting of savings resources, the international banks would only get priority if the potential customer would have three partitions for savings or one third of the potential preferential slots, affirming the hypotheses that indeed local universal banks would have the default local customer preference as attested to by the combined results of a point on point attribute analysis and the preferential conjoint analysis.

The fourth hypotheses that pertains to loans is a different story. With loan-deposit interest differential as one of the biggest sources of revenue for any banks, the nullification of the hypotheses that local customers would still prefer local banks poses serious questions. Knowing that the study's respondents with strong majority, would drop any form of local preferential bias to and apply loans and financing products to international ones would prove a worthy preparatory action for the forth coming revisions to the ASEAN banking competitive environment.

\section{Conclusion}

Knowing how important these findings are, it is worth noting that these value added service and marketing positioning components of the banking industry are crucial in balancing out the competitive instability brought about by the ASEAN Banking Integration Initiative. As determined through the attributes discussed, these marketing intensive elements of the competitive positioning strategy of local banks, who are affected by the ABIF phenomenon should focus on making sure that they look into these aspects of their marketing efforts during and after the full implementation. However without the equally important due diligence to study these data and consider the impact of change as what has been observed as of the time of the study in Philippine banks, all these would not yield benefit for all stakeholders.

\section{Recommendation}

Based on the individual analysis of findings and the match paring analysis for the two data sets derived from the study, the researcher's first recommendation revolves around 
the disparity between the results for Scenario C (On loans and Credit) covering hypothesis 4 and the other scenarios and hypothesis that points out towards savings and account maintenance. Upon analysis of H4's nullification, it seems like local customers are more inclined towards shifting loans and financing services needs towards international competitors and QABs which probably stems out of the logic of owing from an outsider versus entrusting your money to outsiders. As one of the core banking business, loans should be a priority for local banks given that their customers, based from this preference framework produced in this study would light-handedly switch loans services provider. Probably by way of monitoring closely through the local monetary board, the fluctuations of competitive interest rates, or ever all better value propositions. International QABs on the other hand should also hammer on this entry opportunity, given that most of the respondents of this framework would actually steer clear from transferring their deposit funds to international players.

Secondly in terms of taking advantage of the uncovered top priority attributes that customers finds attractive, both categories of banks should consider making these attributes their flagship and marketing battle cry in order to capture as much business as possible.

\section{Direction for future research}

The researcher, based on the preferential framework derived out of this current study, envisions the creation of a predictive model that used the outputs of this current framework as a cornerstone for the said predictive mechanism. The current stage of the integration initiative (ABIF) also provides for a more conducive analytical opportunity for the said model as the actual events of ASEAN unfolds.

Like-wise the researcher also envisions a study about the ASEAN Banking Integration Framework that deals with the potential mergers, acquisitions, and partnerships that may happen within the time frame of the ABIF.

If researchers desire to replicate the objectives of the study to a different member state of the ASEAN region or for any territory, a more detailed sampling of the subject banks which preferably uses the runs test tool for better representation is suggested as well as including the loans application procedure realities according to local territories.

\footnotetext{
Abbreviations

ASEAN: Association of South East Asian Nations that includes Indonesia, Malaysia, The Philippines, Singapore, Thailand, Brunei, Vietnam, Laos, Myanmar, and Cambodia established in August 8, 1967.; AFAS: ASEAN Framework Agreement on Services, based on the GATS or the General Agreement on Trade and Services promulgated by the world bank:; ABIF: ASEAN Banking Integration Framework, the subject of the study and one of the integration initiatives under the ASEAN Economic Community alongside ASEAN Insurance Integration Framework and Services Integration Framework: LPB: Local Preferential Bias. One of the core concepts that guides the comparative analysis nature of the current study, LPB expresses strong inclinations towards a prospective individual's inclination towards adhering to familiar and local service providers.; ESE: Expenditures Switchers Effect. The other half of the study's conceptual framework, this is the opposite of LPB, indicating that value is still prioritized when asked to choose between options. Both are explained further in the review of related literature portion of the study.; AEC: ASEAN Economic Community established December 31, 2015 covering a plethora of integration initiatives:; QAB: Qualified ASEAN Banks. When a universal bank belonging to any member state of the ASEAN Region qualifies to belong to this category, the said bank can freely enter any ASEAN member states free of territorial restrictions in theory.
} 


\section{Funding}

The research has been fully funded by the author.

\section{Author's contributions}

Primary/Corresponding Author is Francis Lawrence B. De Jesus. As the primary researcher most of the manuscript's discussions, primary data solicitation, and analysis was provided by this author. The secondary author is Dr. Enrico Aurelio Torres who acted on an adviser capacity and provided perspectives for the primary author. Both authors read and approved the final manuscript.

\section{Competing interest}

The research has rendered consultancy services to a savings bank in the Philippines, PSBank Corporation from the years 2014 to 2016. Currently the researcher has no connection whatsoever to the said savings bank and is a full time faculty member in the University of Santo Tomas.

\section{Publisher's Note}

Springer Nature remains neutral with regard to jurisdictional claims in published maps and institutional affiliations.

\section{Received: 17 April 2017 Accepted: 13 October 2017}

Published online: 26 October 2017

\section{References}

Abdullahi, NA (2016). Islamic banking in Nigeria: Issues and prospects. Journal of Emerging Economies and Islamic Research, 4(2), 1-14.

Everret, J (2015, November 13). Debacle: The 11th GTA Report on Protectionism. Manila, Metro Manila, Philippines. Retrieved from pubpolice.blogspot.com/2012/06/debacle-11th-gta-report-on.html

Ford, JB (2011). Loacal versus International Appeal Perspective. Journal of Advertising Research, 51(1), $27-41$.

Gallup, PN (2015, November 4). Income Biggest Barrier to Banking in Developing Countries; Costs, proximity, and documentation among obstacles to account ownership. Manila, Metro Manila, Philippines. Retrieved from news. gallup.com/poll/159380/income-biggest-barrier-banking-developing-countries.aspx

Gosh, S (2014). A study of the participation of the private sector companies of India in CSR activities through conjoint analysis. Vision, 6(3), 115-131.

Chen, J, \& Song K (2013). Two - sided matching in the loan market. International Journal of Industrial Organization, 31(1), 145152.

Ke Zhong, HW (2015). Consumers' processing mindset as a moderator of the effect of country of origin product stereotype. Social Behavior \& Personality: 'International Journal of Clinical Psychiatry', 43(8), 1371-1384.

Lianxi Zhou, ZY (2010). Non - local or local brands? A multi - level investigation into confidence in brand origin identification and its strategic implications. Journal of Academic Marketing Science, 38(1), 202-218.

Menon, R (2015, October 6). ASEAN financial integration: Where are we, where next? Retrieved from www.mas.gov.sg

Mongid, A (2016). Global financial crisis and Islamic banks profitability: Evidence from MENA countries. Journal of Emerging Economies and Islamic Research, 1(4), 1-15.

Nofsinger, JR (2012). Familiarity bias in investment. The Financial Review, 47(1), 423-443.

O'Sullivan, RE (2010). Foreign bank presence in emerging markets: Help or hindrance to banking system stability? Applied Economics Letters, 17(7), 623-626.

Osunde, C (2014). A study on customer relationship management practices in selected commercial banks with reference to Nigeria. Journal of Entrepreneurship \& Organization Management, 3(2), 2-6.

Özsomer, A (2012). The interplay between global and local brands: A closer look at percieved brand globalness and local iconess. Journal of International Marketing, 20(2), 72-95.

Punyatoya, P (2013). Consumer evaluation of brand extension for global and local brands. Journal of International Consumer Marketing, 25(1), 195-215.

Sarwar, S, \& Haq Nu (2017). Re-assessing political, social and economic determinants of economic growth: An analysis from selected Asian developing countries. Journal of Emerging Economies and Islamic Research, 5(1), $82-93$.

Seyal, AMN (2011). Customer satisfaction with internet banking in Brunei Darussalam. E services journal, 7(3), 73-82.

Taylor, Charles R (2015). Do brands use simillar exxecutive styles across cultures? A comparison of U.S. and Japanese television advertising. Journal of Advertising', 44(3), 276 - 288.

Victor Petines, RS (2014). How should we bank with foreigners? An empirical assessment of lending behaviors of international banks to six EAST Asian economies. International Review of Economics and Finance, 29(1), 532-568.

Volz, U (2013). ASEAN financial integration in the light of recent European experiences. Journal of Southeast Asian Economies, 30(2), 132.

Zarantorello Lia, BS (2014). How to advertise and build brand knowledge globally. Journal of Advertising Research, 54(4), 420-443. 